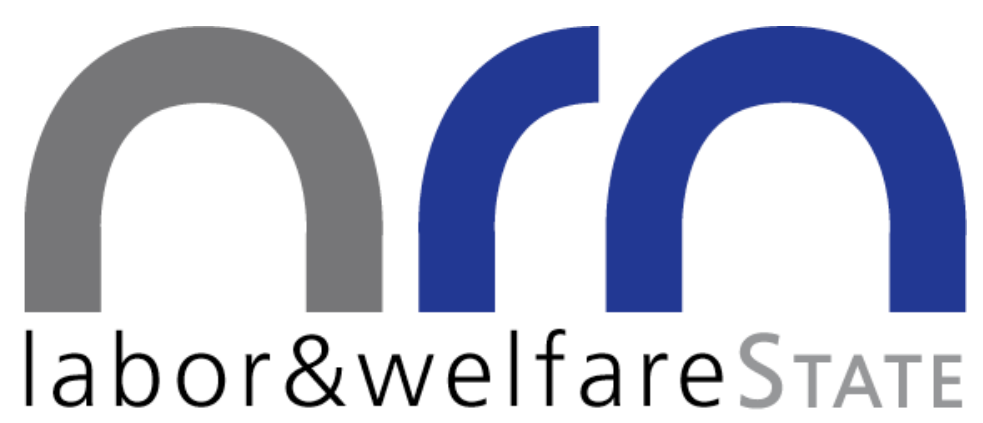

The-Female Gap in Physician Earnings:

Evidence from a Public Health Insurance System

by

Engelbert THEURL, Hannes WINNER

Working Paper No. 1001

January 2010

Supported by the Austrian Science Funds

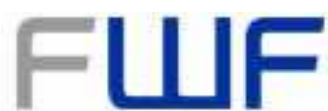

The Austrian Center for Labor Economics and the Analysis of the Welfare State

JKU Linz

Department of Economics

Altenberger Strasse 69

4040 Linz, Austria

www.labornrn.at 


\title{
The Male-Female Gap in Physician Earnings: Evidence from a Public Health Insurance System
}

\author{
Engelbert Theurl ${ }^{\dagger}$ and Hannes Winner ${ }^{\ddagger}$
}

January 2010

\begin{abstract}
Empirical evidence from U.S. studies suggests that, on average, female physicians earn less than their male counterparts. This gap in earnings does not disappear when individual and market characteristics are controlled for. This paper investigates whether a gender earnings difference can also be observed in a health care system predominantly financed by public insurance companies. Using a unique data set of physicians' earnings recorded by a public social security agency in an Austrian province between 2000 and 2004, we find a gender gap in average earnings of about 32 percent. A substantial share of this gap (20 to 47 percent) cannot be explained by individual and market characteristics, leaving labor market discrimination as one possible explanation for the observed gender earnings difference of physicians.
\end{abstract}

JEL classification: I11, I18, J31, J71

Keywords: Health care financing; physician earnings; wage composition

\footnotetext{
${ }^{\dagger}$ Department of Economics and Statistics, University of Innsbruck; Universitaetsstrasse 15, A-6020 Innsbruck, Austria; Engelbert.Theurl@uibk.ac.at.

${ }^{\ddagger}$ Department of Economics and Social Sciences, University of Salzburg; Kapitelgasse 5-7, A-5010 Salzburg, Austria; Hannes.Winner@sbg.ac.at.
} 


\section{Introduction}

Earnings differentials between males and females are a persistent characteristic of virtually every labor market (see, e.g., Blau and Kahn, 2003; Arulampalam, Booth and Bryan, 2007; Olivetti and Petrongolo, 2008; for international evidence). According to the empirical literature, this gap can be only partially explained by individual and market characteristics. The remaining (unexplained) portion is usually attributed to gender discrimination (see, e.g., Cain, 1986; Altonji and Blank, 1999, for comprehensive surveys; Weichselbaumer and WinterEbmer, 2003, 2007; for meta studies). In line with this observation, substantial unexplained gender earnings differentials have also been found in the physician labor market. For instance, Kehrer (1976), analyzing survey data from the American Medical Association, estimates a gender gap in average hourly earnings of about 30 percent. Only a minor part of this difference is explained by individual characteristics such as experience, speciality, or board certification, among others. By and large, the subsequent empirical research lends support to the findings of the Kehrer study (see Langwell, 1982; Ohsfeldt and Culler, 1986; Hampton, 1991; Hampton and Heywood, 1993; Bashaw and Heywood, 2001). ${ }^{1}$

Two characteristics of previous research make it worth to re-examine the gender earnings gap of physicians. First, the existing studies rely on survey data. The obvious disadvantages of survey data in analyzing gender earnings differentials are that female physicians might have lower response rates than male physicians, and, even if this is not the case, they might systematically report lower incomes than male physicians. ${ }^{2}$ Consequently, the estimation results are biased and the role of discrimination probably would be overestimated. Second, the bulk of the empirical papers focuses on U.S. data. The traditional U.S. health care system is characterized by a close relationship between health care providers and patients. A (private) health insurance provider only reimburses a patient's expenditures for physician services if they are included in his insur-

\footnotetext{
${ }^{1}$ One notable exception is Baker (1996). Using data from the 1991 U.S. Survey of Young Physicians he did not find support for a gender wage gap. However, Bashaw and Heywood (2001), re-estimating this study using the same data set, have demonstrated that this result is driven by a misspecification of the earnings function (see footnote 4 below).

${ }^{2}$ One source of differences in reporting might be that females are more risk averse than males, and are, therefore, less likely to overstate their income. This presumption is confirmed by Rizzo and Zeckhauser (2006), who find that the difference between the reported income and the self-designated reference income is much lower for female physicians. Further, survey data are inherently confronted with a possible selection bias, which in our context would arise if low-income earners (females) have different response rates than high-income earners (males). For example, Wood, Corcoran and Courant (1993, footnote 8), analyzing the gender gap in lawyers' salaries, provide evidence for such a selection bias.
} 
ance plan. This, together with differences in the risk coverage among patients, allows physicians to maximize income by setting prices discretionary (the increased market share of Managed Care Organizations in the 90's has reduced the scope for such price setting strategies; see Glied, 2000, for further details). In contrast, in health care systems with traditionally strong public health insurance providers, prices are usually agreed ex ante between the public insurance company and representatives of the physicians. Under such a health care system, it is ambiguous whether the gender earnings gap is higher or lower than in a more privately financed system. On the one hand, a single physician does not have control over the prices of medical services and, hence, only a moderate influence on his earnings. In this case, income inequalities among male and female physicians should be less important. On the other hand, the regulation of prices inhibits competition. Becker's (1957) seminal work on the economics of discrimination demonstrated that increased market competition would reduce or eliminate discrimination against disadvantaged groups (see Ashenfelter and Hannan, 1986; Black and Strahan, 2001; Hellerstein, Neumark and Troske, 2002; for empirical evidence). In that case, we would expect a higher gender earnings gap. After all, it remains an empirical question whether a gender differential in physician earnings depends on the type of financing health care services.

This paper contributes to the empirical research on the gender discrepancy of physician earnings in two ways. First, we use data from a public health insurance system based on Bismarckian principles. Second, we rely on earnings data recorded by the public social security company rather than income reported by the physicians. In particular, we refer to a panel of annual physicians' earnings in the Austrian province of Tyrol between 2000 and 2004. This unique data set gives us the opportunity to address both of the aforementioned limitations in the previous literature. Apart from that, we are able to exploit more detailed information on the individual characteristics of physicians, especially on their activity levels (e.g., the number of patients treated within a year) and their case-mix.

In our sample, we observe a gender earnings gap of about 32 percent. Applying the Blinder-Oaxaca framework to decompose the earnings differentials, we find that a substantial part of this difference cannot be explained by individual and market characteristics (i.e., approximately 20 to 47 percent, depending on the assumption about non-discriminatory earnings). In qualitative terms, these results are well in accordance with previous studies, suggesting that discrimination is a robust and persistent phenomenon in the physician labor market, 
regardless of whether the health care system is dominated by private or public health insurance providers.

The remainder of this paper is organized in the following way. Section 2 describes the Austrian payment system for outpatient care. Section 3 presents the data and the estimation method and discusses the empirical findings. The last section summarizes our findings.

\section{Physician payment in Austria}

After obtaining a Doctor of Medicine degree (Dr. med.), which requires a minimum of six years full-time study (currently, the median time is 8 years), a physician has to complete a medical training at an authorized institution (in most cases a hospital). At that time, physicians choose their future specialization, i.e., either to work as a general practitioner (with a training of three years) or to become a medical specialist (six years). Due to limited capacities there is usually a waiting time between two and three years for medical training. Currently, an Austrian physician receives his final degree and, hence, the license for practice at the age of 33 (general practitioners) or 36 (specialists), on average. This license authorizes the physician (i) to work in a public (or private) hospital on a salary basis, (ii) to offer medical services as a 'private' physician in the outpatient health care sector, or (iii) to apply for a contract with a public health insurance provider. Physicians that belong to (ii) and (iii) are self-employed. Our study focuses exclusively on (iii).

The public health insurance system is the dominating sector of the Austrian health care system, especially in outpatient care. Public insurance is obligatory for the working population (i.e., employees and self-employed); family members (i.e., spouses and children) have access to health insurance coverage without extra payments if they are not insured by themselves. The system is regulated by legislation at the federal level and operates under the supervision of the Federal Ministry of Health. It mainly relies on income-based contributions. Its structure is determined with respect to territorial and occupational considerations, and it is organized by representatives of employers and employees. Roughly 98 percent of the Austrian population is covered under the public health insurance. 80 percent of the covered population (mainly employees in the private sector and their family members) has an insurance plan with a public health insurance company at the provincial level, called 'Gebietskrankenkasse'.

Public outpatient care is predominantly offered on a contractual basis. There is a basic agreement between the Main Association of Social Insurances 
(acting as an agent for public health insurance companies) and the Chamber of Physicians at the level of provinces (acting as agent for the physicians). This agreement determines the terms and conditions for the regional supply of publicly financed outpatient care. More specifically, it defines the density of physicians per speciality, their regional distribution, important dimensions of the practice style (e.g., office hours, treatment guidelines, limitations on secondary employment) and the physician payment scheme, among others. Within this regulatory framework, a physician can apply for a contract. Once concluded, a contract is not limited in time. The assignment of contracts is based on criteria such as date of application, professional experience, or additional medical qualifications. In our context, it is important to note that gender does not (officially) constitute a relevant criterion for the offering of a contract. Further, we would like to emphasize that the public outpatient sector in Austria can be characterized as a "cottage industry" where sole proprietorship dominates; integrated forms of health care (e.g., group practices or gatekeeping mechanisms) are significantly underdeveloped. Consequently, the contracts are typically signed by the physicians individually.

Currently, about 50 percent of all physicians working (fulltime or part time) in outpatient care work under a contract with a public health insurance company. However, the share of physicians without a contract has grown steadily over time. One reason is that the number of physicians with a license to practice has increased substantially in the last years. In addition, the Main Association of Social Insurances and the Chamber of Physicians at the provincial level have become more restrictive in offering contracts. As a consequence, waiting lists of physicians seeking a contract have become longer and longer. Further, the age at which a physician typically obtains a contract increased sharply from around 33 years in 1973 to about 47 years in 2004 .

Contracted physicians generate income from fee-for-service and lump-sum payments. Lump-sum payments can be claimed for initial contacts per quarter and for the provision of basic medical services (e.g., medical consulting, home visits). The share of lump-sum payments to total physician earnings varies widely over different fields of specialization. At an aggregate level for Austria it amounts to about 68 percent for general physicians and around 34 percent for specialists (specialists for diagnostic services excluded), on average (these values belong to 2003). Details of the remuneration scheme itself are defined in the aforementioned agreement between the Main Association of Social Insurances and the Chamber of Physicians at the level of provinces. Among others, it includes a pre-defined catalogue of services (treatments) that a physician is 
allowed to charge as well as the corresponding prices (fees). In other words, contracted physicians are unable to set prices by their own.

The fee-for-service system works as follows. Generally, each physician receives a pre-defined score ('points') per treatment. At the end of the accounting period, these points are added up to calculate the total sum of scores. Then, a monetary value is assigned to each point per treatment, which, in turn, depends on the total number of points for the relevant accounting period. However, to avoid a supplier induced demand inherently present in a fee-for-service system, the system is capped by two mechanisms. In a first step, payments are limited to a certain number of treatments per patient and time (e.g., general practitioners and most specialists receive a maximum of 29 points per patient and quarter). Additional treatments above this threshold are not remunerated by the public insurance system, implying zero marginal earnings. In a second step, total payments are 'tapered' in the sense that the marginal monetary payment per point decreases with the total number of points and, therefore, with the number of treatments. For example, general practitioners and most specialists receive a monetary value of EUR 0.8913 per point if the total score is below 28,000 points per year, EUR 0.4477 between 28,001 and 36,000 points, and a value of EUR 0.2235 above 36,001 points per year.

Physicians are allowed to earn extra money by providing additional services 'beyond' the contract. Most importantly, physicians may (i) offer services to private patients, (ii) supply services to patients of other public insurance companies (e.g., the one of public employees), (iii) work in a public or private hospital, or (iv) volunteer for special tasks within the health care system (e.g., services at schools). Further, general practitioners in remote areas are allowed to run a pharmacy if there is no commercially operated pharmacy in an appropriate distance. ${ }^{3}$ All of these side-line employment activities are strongly regulated by the physician contract (e.g., by upper limits of working hours in these occupations).

With regard to earnings gaps between male and female physicians it is important to note that the remuneration scheme does not include direct incentives for the provision of services to specific groups of patients (e.g., for one and the same treatment, there are not extra payments for treating older patients) or to locate to remote areas. Further, there is no specific monetary (dis-)advantage for female physicians. Therefore, a gender earnings differential is not embedded

\footnotetext{
${ }^{3}$ Therefore, it is not their own decision to operate a pharmacy. The supply of pharmaceuticals is regulated in the same way as for commercially held pharmacies. Additional revenue generated from the operation of own pharmacies and other secondary employment options are not included in our earning figures reported below (Table 1).
} 
in the remuneration scheme.

Finally, people are also allowed to draw on the medical services of physicians without a contract (private physicians). In contrast to contracted physicians, private physicians are more or less free to set prices for their services; there are only unbinding recommendations from the Chamber of Physicians. However, since patients receive a lower reimbursement under a public insurance plan if they claim for private physicians' services, the demand for their services is relatively modest. Our interest is on the gender earnings gap of contracted physicians (i.e., ones with no influence on prices). Further, earnings data of private physicians are not collected by the social security companies and are, therefore, not available. For these reasons, earnings data of private physicians are not included in the following empirical analysis.

\section{Empirical Analysis}

Data and descriptive statistics: Our sample includes data from 504 physicians (441 males and 63 females) with a public insurance contract in the Austrian province of Tyrol for the period of 2000 to 2004. Overall, the dataset contains about 2,000 observations (the descriptive statistics are reported in Table A1 in the Appendix; the data sources are described in the Appendix). Table 1 summarizes the distribution of the areas of specialization, the mean annual earnings and individual characteristics by specialization and sex, averaged over the sample period. Notice that earnings are not identical to income (revenue minus cost of running a practice), but it only covers the amount a physician charges to the public insurance system for medical services (see Fujisawa and Lafortune, 2008, for a similar definition). Additional earnings from other medical services (e.g., emergency doctor, school district doctor or income from a pharmacy) are not included in our data set.

On average, the annual gross earnings of a male physician are EUR 195,575 (before taxes and social contributions), corresponding gross annual earnings for a female are only EUR 154,155, or 76.1 percent of male earnings. The average gender earnings gap amounts to 31.4 percent, varying widely over the areas of specialization (from 139 percent for pediatrics to around -3 percent for dermatology). It varies widely over the specializations; from -37.0 percent for other specializations to 58.3 percent for pediatrics.

$>$ Table $1<$ 
One explanation for the gender earnings gap might be that female physicians are relatively over-represented in specializations at the lower tail of the income distribution (e.g., such as general practice or pediatrics). This seems not to be the case in our sample (see Table 1). Perhaps more striking, however, is the fact that female physicians work less than male ones (on average, 1.1 hours a week). Correcting for this difference by calculating earnings per hour at an annual basis, we obtain a gender earnings gap of EUR 27.9 (or 20.2 percent). Hence, even if differences in working hours are accounted for, the earnings differential between male and female physicians remains considerably large. Next, Table 1 shows two variables that are often considered as important sources of the gender earnings gap, i.e., age and residential length (i.e., years since conclusion of the contract). Both variables are typically used to approximate work experience (e.g., Ohsfeldt and Culler, 1986). On average, we observe a gender difference in age (residential length) of about 1.2 (2.2) years, indicating that work experience might be an important source of the gender earnings gap.

Finally, one might suspect that different working styles and activity levels between female and male physicians might contribute significantly to the explanation of the observed difference in earnings. In this regard, we collected data on the number of patients and on the number of treatments per physician. Both variables account for the productivity of physicians (see Kehrer, 1976; Langwell, 1982). Further, our sample contains information on the demand for physician services of three age groups: young patients (below 30 years), patients between 31 and 60 years, and elderly (above 60 years). Then, we calculated the shares of patients in each of these age groups to the total number of patients. Table 1 reports the average number of patients per hour (column 8), the average number of treatments per hour (column 9) and the aforementioned shares of patient groups (columns 11 to 12). As can be seen from Table 1, a physician treats about four patients or reports 37 treatments per hour, on average. Further, we observe a systematic difference in activity levels between males and females which amounts to about 11 and 16 percent, respectively. This is broadly in line with Constant and Léger (2008) who investigate gender differences in physicians services in Canadian provinces. Their findings suggest that female physicians provide significantly less services than their male counterparts. However, columns 10 to 12 of Table 1 indicate that the observed difference in activity levels cannot be explained by the services provided to different age cohorts. We only find slightly lower relative activity levels of female physicians in the group of older patients.

In sum, the descriptive analysis of the data illustrates that it is inevitable 
to account for individual characteristics when analyzing earnings differentials between male and female physicians. In the following, we provide a systematic approach to analyze the role of individual and market characteristics for the observed physician gender earnings differential.

Specification and estimation: To disentangle the sources of the observed earnings gap we use a standard wage decomposition as proposed by Blinder (1973) and Oaxaca (1973). First, we estimate a Mincer-type earnings equation for males and females separately (see Rizzo and Blumenthal, 1994, for a related physician earnings function),

$$
\begin{gathered}
y_{i t, m}=\mathbf{x}_{i t, m}^{\prime} \boldsymbol{\beta}_{m}+\nu_{i t, m}, \\
y_{i t, f}=\mathbf{x}_{i t, f}^{\prime} \boldsymbol{\beta}_{f}+\nu_{i t, f},
\end{gathered}
$$

where $y_{i t}$ is the log of annual earnings of the $i$-th physician in year $t$, and the subscript $m(f)$ indicates that the sample is restricted to males (females). $\mathbf{x}$ is a vector of individual characteristics comprised of individual work experience (i.e., working hours per week and non-working days per week interacted with a variable indicating whether the physician offers services by appointment) ${ }^{4}$ and the experience of the physician (i.e., age and its square, as well as the residential length since the starting year of the contract). It further includes variables that account for market characteristics (e.g., population and per capita income) and market competition in outpatient care (see Becker, 1957). The latter is captured by including the number of physicians in the medical district with and without a contract (at the level of provinces, the Austrian health care system is subdivided in medical districts). Finally, $\mathbf{x}$ also includes a set of dummy variables for each of the specializations and additional individual characteristics of the physicians (e.g., whether the physicians runs a pharmacy). ${ }^{5}$ Note that the intercept, which serves as the reference group, is also included in $\mathbf{x} .{ }^{6}$ In our

\footnotetext{
${ }^{4}$ Most of the empirical studies implicitly include working hours as a left-hand side variable by defining the log of hourly wages of physicians as the dependent variable (e.g., Baker, 1996). However, Bashaw and Heywood (2001) have demonstrated that the true influence of hours worked is inappropriately captured by such a specification. Hence, we follow their suggestion and include the log of working hours on the right-hand side of (1) and (2) (see Wood, Corcoran and Courant, 1993; Smith, 2002, for similar earnings equations).

${ }^{5}$ To account for time dependencies in earnings we also estimated alternative specifications including (i) time effects or (ii) a time trend in (1) and (2). It turned out, however, that they were insignificant in both the female and male regressions.

${ }^{6}$ Oaxaca and Ransom (1999) have demonstrated that the combined estimated contributions of all dummy variables to overall unexplained parts (including the constant) and to overall explained parts are not sensitive to the choice of the reference group. The choice of the reference group would be only critical if the interest lies on the separate impact of the dummy
} 
case, the reference group are the general practitioners, and the corresponding parameter estimates are reported in the constant term. $\nu$ is an identically and independently distributed stochastic error term.

Estimating both equations with (pooled) OLS (e.g., Ohsfeldt and Culler, 1986), ${ }^{7}$ and subtracting (2) from (1) yields

$$
\begin{aligned}
\bar{y}_{m}-\bar{y}_{f} & =\overline{\mathbf{x}}_{m}^{\prime} \hat{\boldsymbol{\beta}}_{m}-\overline{\mathbf{x}}_{f}^{\prime} \hat{\boldsymbol{\beta}}_{f} \\
& =\underbrace{\overline{\mathbf{x}}_{m}^{\prime}\left(\hat{\boldsymbol{\beta}}_{m}-\boldsymbol{\beta}^{*}\right)+\overline{\mathbf{x}}_{f}^{\prime}\left(\boldsymbol{\beta}^{*}-\hat{\boldsymbol{\beta}}_{f}\right)}_{\text {unexplained part }}+\underbrace{\left(\overline{\mathbf{x}}_{m}^{\prime}-\overline{\mathbf{x}}_{f}^{\prime}\right) \boldsymbol{\beta}^{*}}_{\text {explained part }}
\end{aligned}
$$

where $\bar{y}_{m}\left(\bar{y}_{f}\right)$ and $\overline{\mathbf{x}}_{m}^{\prime}\left(\overline{\mathbf{x}}_{f}^{\prime}\right)$ are the means of $y_{i t, m}\left(y_{i t, f}\right)$ and $\mathbf{x}_{i t, m}^{\prime}\left(\mathbf{x}_{i t, f}^{\prime}\right)$, respectively (a 'hat' indicates estimated parameters from (1) and (2)). $\boldsymbol{\beta}^{*}$ is a vector of the non-discriminatory earnings structure, defined as

$$
\boldsymbol{\beta}^{*}=\boldsymbol{\Omega} \hat{\boldsymbol{\beta}}_{m}+(\mathbf{I}-\boldsymbol{\Omega}) \hat{\boldsymbol{\beta}}_{f}
$$

$\boldsymbol{\Omega}$ is a (diagonal) weighting matrix of dimension $K$ (i.e., the number of regressors), and $\mathbf{I}$ is the identity matrix. Following the original BlinderOaxaca decomposition we assume $\boldsymbol{\Omega}=\mathbf{I}(\boldsymbol{\Omega}=0)$, indicating that the nondiscriminatory earnings are those of male (female) physicians. In the former case, it is implicitly assumed that discrimination penalizes the low-income group (in our case females) by preventing them to obtain the wages of high-income earners. In the latter case, we assume that discrimination favors the highincome group by receiving a higher wage as in a world with non-discriminatory earnings. Since non-discriminatory earnings might be somewhere in between these two extremes in reality, we use three alternative weighting schemes: (i) $\boldsymbol{\Omega}=0.5 \mathbf{I}$ (see Reimers, 1983); (ii) $\boldsymbol{\Omega}=s_{f} \mathbf{I}$, where $s_{f}$ is the share of female physicians to total physicians (see Cotton, 1988). In our sample $s_{f}$ is 0.155 (see Table A1 in the Appendix); (iii) $\boldsymbol{\Omega}=\left(\mathbf{x}_{m}^{\prime} \mathbf{x}_{m}+\mathbf{x}_{f}^{\prime} \mathbf{x}_{f}\right)^{-1} \mathbf{x}_{m}^{\prime} \mathbf{x}_{m}$ (indices $i$ and $t$ are suppressed for the sake of brevity) which is equivalent to using the parameter estimates of $\boldsymbol{\beta}$ from the pooled sample (see Neumark, 1988; Oaxaca and Ransom, 1994).

To illustrate the interpretation of (3), let us assume that $\boldsymbol{\Omega}=\mathbf{I}$. Then,

variables on discrimination (see Jones, 1983; Oaxaca and Ransom, 1999).

${ }^{7}$ It should be noted that the estimation of a standard fixed effects panel data model is not applicable here, since the fixed male effects are wiped out in the female regression, and vice versa. Using a random effects model we obtain similar results as in our specification, especially with regard to the earnings decomposition. However, the Hausman test has to be rejected indicating that the random effects estimator is inconsistent (see, e.g., Baltagi, 2005, pp. 66). Hence, we do not report these findings, but they are available from the authors upon request. 
(3) reads as $\bar{y}_{m}-\bar{y}_{f}=\overline{\mathbf{x}}_{f}^{\prime}\left(\hat{\boldsymbol{\beta}}_{m}-\hat{\boldsymbol{\beta}}_{f}\right)+\left(\overline{\mathbf{x}}_{m}^{\prime}-\overline{\mathbf{x}}_{f}^{\prime}\right) \hat{\boldsymbol{\beta}}_{m}$. The second part on the right-hand side evaluates the difference in earnings at the mean values of the independent variables using male coefficients. It informs about the gender earnings differential explained by the regressions. The first part on the righthand side captures additional earnings a female physician would earn if she were treated as a male. This is the unexplained portion of the earnings gap and is usually assigned to discrimination.

Estimation results: Table 2 reports the regression results of the male and female earnings equations along with the mean of the independent variables. The last two columns show the explained portion of the earnings gap as defined in the last term on the right-hand side of (3) using male $(\boldsymbol{\Omega}=\mathbf{I})$ and female coefficients $(\boldsymbol{\Omega}=0)$ as non-discriminatory earnings. In all regressions, we correct for outliers by dropping observations in the upper and lower tail of the error term (i.e., approximately two percent of the sample). To account for a potential heteroscedasticity we report White-robust standard errors (see White, 1980).

The coefficients of the regressors are almost as expected and also consistent with studies using U.S. data. Working hours are positively related to earnings (see Bashaw and Heywood, 2001). Further, the positive coefficient for the interaction term between days not worked and the dummy variable of services by appointment suggests that physicians working outside the official opening hours earn a higher income, all else equal. ${ }^{8}$ In accordance with earlier studies, age (age squared) enters significantly positive (negative) - at least in the male regression - indicating a positive but diminishing impact of a physician's work experience on annual earnings (see, e.g., Kehrer, 1976; Langwell, 1982; Ohsfeldt and Culler, 1986; Bashaw and Heywood, 2001). Residential length exhibits a positive impact on earnings, which is also in line with previous research (see Ohsfeldt and Culler, 1986). Furthermore, we find significant positive effects for all areas of specialization but pediatrics in the male regressions, and also significantly positive ones for pediatrics and other specialities in the female regressions.

With regard to the activity levels of physicians, we include (i) the total number of treatments per physician and year, (ii) the share of patients aged between 31 and 60 to the total number of patients, and (iii) the share of patients older than 60 to the total number of patients (to avoid collinearity, the share of

\footnotetext{
${ }^{8}$ About ten percent of the physicians do not work at least one day in a (five day working) week. Around 28 percent offer services by appointment outside the official opening hours.
} 
patients younger than 30 to the total number of patients serves as the reference group). Since payment for services usually varies over the age of patients, one might expect that (ii) and (iii) enter significantly in our gender-specific earnings regressions. However, the sign of these variables is not clear a priori: On the one hand, the frequency of doctor visits tends to increase with age, so that we expect higher earnings for physicians treating more older patients. On the other hand, services on older patients might be more time-consuming, implying reduced earnings, on average. With regard to (iii), we would expect a positive impact on earnings. In our case, the price per treatment is fixed by the social insurance company, and, therefore, an increase in treatments per time unit should automatically be associated with an increase in earnings. The estimation results from Table 2 suggest that all variables indicating a physician's activity level exert a significantly positive impact on earnings (with the exception of the share of patients between 31 and 60 years which is insignificantly negative in the male regression).

$>$ Table $2<$

To account for additional individual characteristics of physicians, we include (i) a dummy variable with entry one if a physician runs a pharmacy by herself and zero otherwise (which is the case for about 18 percent of physicians in the sample); (ii) a dummy variable for each of three additional characteristics a physician may hold: emergency physician certificate (46 percent), school physician (2.5 percent), and medical district doctor including specific tasks of public health (e.g., control of epidemics) and the provision of medical services on Sundays and holidays (17 percent); and (iii) a categorical variable indicating whether the physician has a temporary outside appointment (18.6 percent of the sample). ${ }^{9}$ As can be seen from Table 2 , most of these variables take the expected signs. A pharmacy held by a physician reduces earnings, on average, which might be explained by the fact that pharmacies are only allowed to be operated in rural areas where physician income is lower. Outside appointments enter significantly positively with regard to the indicator variable of emergency certificate, but insignificantly for the other two functions (i.e., medical district

\footnotetext{
${ }^{9}$ Specifically, the variable takes the following entries: '1' in the case of a public hospital, '2' for a private hospital, '3' for other social insurance institutions, and '4' for other health care institutions outside the hospital sector (e.g., rehabilitation centers). In all other cases (i.e., no temporary appointments outside), the variable is zero.
} 
doctor and school physician). Temporary appointments outside the ordination exhibit a negative but insignificant impact on annual earnings, which is consistent with Bashaw and Heywood (2001).

To control for the most important market characteristics and the specific economic situation of a province, which may influence the income situation of physicians, we use the following information at the level of local jurisdictions (municipalities and cities): (i) per capita income, (ii) population, (iii) living area, (iv) number of tourist accommodations, and (v) the number of net commuters (i.e., difference of in- and out-commuters). As can be seen from Table 2, we observe significant effects of per capita income, population size, living area and tourist accommodations (population, living area, tourist accommodations and commuters) in the male (female) regression. Tourist accommodations exhibit a negative effect on earnings which seems reasonable given the fact that medical services for tourists are usually not covered under a public insurance plan; therefore, they are not included in our earnings data.

Further, we account for market concentration in the outpatient care as measured by the number of physicians in the medical district (i) with and (ii) without a contract. Considering these variables allows to analyze whether discrimination is negatively related to market competition as discussed above (see Becker, 1957). In our regressions, we find significantly positive effects for the number of contracted physicians and significantly negative ones for private physicians. This, in turn, indicates that competition regarding private physicians tend to lower the income of contracted physicians, while competition in the contracted physician market increases income. The latter result might be driven by referrals from general (contracted) physicians to contracted specialists. Finally, we include the proportion of female to male physicians at the level of medical districts. In this regard, Hampton (1991) has demonstrated that the decomposition of physicians' earnings leads to biased results as long as this variable is not controlled for. In accordance with earlier evidence from labor market studies, he finds that the income of both males and females is negatively associated with the share of female physicians and that this effect is more pronounced for males. For instance, if health care utilization was influenced by potentially different treatment styles between males and females we would expect such an effect in our case. In our sample, we obtain insignificant parameter estimates for this variable.

Overall, when using the male (female) coefficients as non-discriminatory earnings about $0.172(0.274)$ of the total earnings gap can be explained by individual 
and market characteristics (see the last two columns of Table 2). In other words, gender differences in individual and market characteristics generate an absolute gender earnings differential of about 17.2 percent. Relying on male coefficients, most of the earnings gap is due to gender differences in experience and activity levels (see the bold entries in the table; a negative entry indicates that the unexplained earnings gap widens when considering the gender difference in a specific variable group). For instance, the three experience variables age, age squared and residential length account for 3.9 percent of the difference in earnings, which is equal to about one quarter of the total explained earnings differential of 17.2 percent. About 70 percent of the explained earnings gap is due to differences in activity levels. Using female coefficients, we find that experience, activity levels and market characteristics is the most influential set of variables. With regard to activity levels, the main share of the explained part is due to the number of treatments. As discussed above, this variable should measure the productivity of physicians. If female physicians charged fewer treatments than their male counterparts they would be less efficient and, therefore, they would obtain systematically lower earnings than male physicians (see Langwell, 1986, for a detailed discussion). The positive coefficients reported in the last two columns of Table 2 indicate that this seems to be the case in our sample of Tyrolean physicians.

The positive value of market concentration in both male and female representation indicates that the unexplained part of the earnings gap is lower in a competitive environment which is consistent with the aforementioned hypothesis of Becker (1957) and the corresponding empirical evidence (see Ashenfelter and Hannan, 1986; Black and Strahan, 2001; Hellerstein, Neumark and Troske, 2002). However, this entry should be interpreted with caution as it is a result of positive and negative coefficients for sub-components of physician competition.

Decomposition of the gender earnings gap: As can be seen from Table 3 , the overall difference in log earnings is significant and amounts to 0.323 (or 32.3 percent) which comes close to the results in previous studies (especially Kehrer, 1976; Langwell, 1992; Bashaw and Heywood, 2001). The share of explained factors is 0.172 in absolute value (53.2 percent of the total earnings gap). The remaining part, around 15.1 percent (equal to 46.8 percent of the total gender gap), is due to unexplained factors. ${ }^{10}$

\footnotetext{
${ }^{10}$ Regarding the above described earnings decomposition Ohsfeldt and Culler (1986) emphasize that one obtains biased results if the assumption of log-normally distributed error terms is violated. To account for this potentially violated assumption we undertake a sensitivity check by applying two alternative approaches for decomposition as proposed by Ohsfeldt and
} 
The lower block of Table 3 summarizes the results for alternative assumptions on the non-discriminatory earnings. As expected, using female coefficients to decompose the earnings gap reduces the share of unexplained factors substantially to about 15 percent. However, this entry is insignificant, so that a value of 20 percent (from the Cotton-decomposition) seems a more reliable lower bound for the unexplained gender earnings gap.

$>$ Table $3<$

It might further be of interest to analyze how the total earnings differential and its unexplained part have changed over the course of the years. To address this question, we estimate (1) and (2) for each year separately and calculate earnings decompositions as in Table 3. The results are shown in Figure 1. Entries in the upper region of the graph inform about the total earnings gap. Further, Figure 1 plots upper and lower bounds of the unexplained earnings gap as represented by our decomposition approaches discussed above (and reported in Table 3). Entry '*' indicates significance at least at the 10 percent level. As can be seen from the figure, the entries of the lower bounds are insignificant with the exception for the first entry. The reason is that the sample only includes 63 female observations per annum, rendering the parameter estimates in the female representations less reliable than the ones in the male representations. Hence, the lower bounds in Figure 1 should be interpreted with caution.

\section{$>$ Figure $1<$}

From 2000 to 2002, the gender earnings differential decreased from 34.8 to 28.6 percent. Since then, it increased to 31.1 percent in 2003 and 33.2 percent in 2004. With respect to the unexplained gender gap we do not find significant changes between 2000 and 2004. While the upper bounds remain relatively stable within a range of around 40 to 50 percent, the lower bounds declined from 38 percent in 2000 to 23.4 percent in 2004. As mentioned above, these results are not significant and, therefore, we hardly can interpret the lower bounds as evidence for a diminishing role of the unexplained earnings

Culler (1986). It turns out that the shares of unexplained factors are slightly below the ones with male coefficients. For the sake of brevity, we do not report these results here, but they are available from the authors upon request. 
gap. Overall, Figure 1 confirms that the unexplained earnings differential left more more or less unchanged, although the total gender gap slightly decreased over the sample period. Hence, to the extent that the unexplained earnings differentials can be interpreted as discrimination (see the discussion below), our results clearly point to a considerable and persistent role of discrimination in the Tyrolean physician labor market.

Finally, it is encouraging to compare our results to the findings of the existing research. In this regard, two strands of literature have to be considered. First, studies on the (general) gender wage differential in the Austrian labor market suggest an overall income gap of about 25 to 30 percent. For instance, a recent study by Böheim, Hofer and Zulehner (2007) reports an overall gender wage gap of about 25 percent and a share of discrimination of around 60 to 70 percent (see also Ponthieux and Meurs, 2005; Arulampalam, Booth and Bryan, 2007; Olivetti and Petrongolo, 2008; for similar evidence from the Austrian labor market). Further, they find that the wage differential increases with income (see also Arulampalam, Booth and Bryan, 2007; Olivetti and Petrongolo, 2008). Given that physicians belong to the group of high-income earners, our findings seem to be in line with this evidence. Second, previous work based on U.S. physicians' income indicates substantial gender earnings differentials and also a large share of unexplained factors. For instance, Kehrer (1973) observes an earnings differential of 36 percent and an unexplained share of around 70 percent (see Hampton, 1991, for similar results). Bashaw and Heywood (2001) provide somewhat higher estimates of the total earnings gap (around 50 percent) but lower ones for the unexplained earnings gap (around 20 to 30 percent), and Langwell (1982) finds a total earnings gap of 30 percent but a similar share of unexplained factors as in the Kehrer study. The corresponding estimates of our study are broadly lying within this range. This, in turn, raises the question on the sources of discrimination.

The main distinction between our findings and the previous literature on gender earnings gaps in physician earnings is that we explicitly control for pricing and activity levels which are often considered as natural candidates to explain the unexplained share of the gender earnings gap (see, e.g., Langwell, 1982). However, the similarity between our results and that in previous research indicates that there are obviously more important explanations for the observed discrimination in the physician labor market. Possible sources of discrimination might be, for example, preferential treatments of male physicians to enter the market (i.e., privileges in contract assignment), the referring behavior of general 
practitioners (representing the gatekeepers in the Austrian health care system) or gender-biased demand for health services. Apart from that, it has to be taken into consideration that at least parts of the unexplained earnings differential might result from differences in unobservable skills and factors (e.g., ambitions, different work-leisure allocations between male and female physicians) other than discrimination. As pointed out by Ohsfeldt and Culler (1986), we should therefore interpret the unexplained part of the observed earnings differential as an upper bound of the influence of discrimination.

\section{Conclusions}

This paper studies earnings differentials between male and female physicians. It extends the previous empirical research using physicians earnings data recorded by a social security agency rather than survey data (self-reported income). Further, relying on earnings data from an Austrian province we refer to a system with dominating public health insurance providers, which, compared to a U.S. typed private health care system, gives physicians less possibilities to directly influence their income. Specifically, we use a panel of earnings of physicians in an Austrian province between 2000 and 2004. To the best of our knowledge, such a data set has not yet been analyzed. Empirically, we apply a BlinderOaxaca approach to decompose the earnings gap into an explained and an unexplained share.

Our findings can be summarized as follows. In accordance with existing studies, we observe a gender earnings differential of about 32 percent. Although this gap can be largely explained by individual and market characteristics, a substantial portion of unexplained differences remains. Depending on the assumption about non-discriminatory earnings, we find that the share of unexplained factors to the total earnings gap lies within a range of 20 to 47 percent. Although the gender earnings gap has slightly decreased between 2000 and 2004, there is no indication that the unexplained part of this gap has reduced over the course of years. This evidence suggests that gender earnings equality has not been achieved in the Austrian physician labor market. It further reveals that gender differences in earnings are a robust and persistent phenomenon in the physician labor markets, irrespective of whether the health care system is dominated by private companies or public social insurance providers. 


\section{Acknowledgements}

We are grateful to Martin Halla, Sven Jost, Andrea Leiter, Michael Pfaffermayr, Gerald Pruckner, Rupert Sausgruber, Peter Zweifel and the seminar participants at the 6th World Congress of the International Health Economics Association in Copenhagen 2007, at the Annual meeting of the Verein fuer Socialpolitik in Munich 2007 and the University of Salzburg for helpful comments and suggestions. Financial support from the Austrian Fond zur Förderung der wissenschaflichen Forschung (FWF, grant no. S10306-G14) is gratefully acknowledged.

\section{References}

Altonji, J.G. and R.M. Blank, 1999, Race and gender in the labor market, in O. Ashenfelter and D. Card (eds.), Handbook of Labor Economics, Vol. 3, Part 3, Amsterdam: Elsevier Science Publishers, 3143-3259

Arulampalam, W., A.L. Booth and M.L. Bryan, 2007, Is there a glass ceiling over Europe? Exploring the gender pay gap across the wage distribution, Industrial and Labor Relations Review 60, 163-186

Ashenfelter, O. and T. Hannan, 1986, Sex discrimination and product market competition: The case of the banking industry, Quarterly Journal of Economics, 101, 149-173

Baker, L., 1996, Differences in earnings between male and female physicians, New England Journal of Medicine 334, 960-964

Baltagi, B.H., 2005, The econometrics of panel data, 3rd ed., Chichester: John Wiley \& Sons.

Bashaw, D.J. and J.S. Heywood, 2001, The gender earnings gap for US physicians: Has equality been achieved?, Labour 15, 371-391

Becker, G.S., 1957, The economics of discrimination, Chicago: University of Chicago Press

Blau, F.D. and L.M. Kahn, 2003, Understanding international differences in the gender pay gap, Journal of Labor Economics 2003, 106-144

Black, S. and P.E. Strahan, 2001, The division of spoils: Rent-sharing and discrimination in a regulated industry, American Economic Review 91, 814831

Blinder, A.S., 1973, Wage discrimination: Reduced form and structural estimates, Journal of Human Resources 8, 436-455 
Böheim, R., H. Hofer and Ch. Zulehner, Ch., 2007, Wage differences between Austrian men and women: Semper idem?, Empirica 34, 213-229

Cain, G.C., 1986, The economic analysis of labor market discrimination: A survey, in O. Ashenfelter and R. Layard (eds.), Handbook of Labor Economics, Vol. 1, Amsterdam: Elsevier Science Publishers, 693-785

Constant, A. and P.T. Léger, 2008, Estimating differences between male and female physician service provision using panel data, Health Economics 17, $1295-1315$

Cotton, J., 1988, On the decomposition of wage differentials, Review of Economics and Statistics 70, 236-243

Fujisawa, R. and G. Lafortune, 2008, The remuneration of general practitioners and specialists in 14 OECD countries, OECD Health Working Papers No. 14, Paris: OECD Publishing

Glied, S., 2000, Managed Care, in A.J. Culyer and J.P. Newhouse (eds.), Handbook of Health Economics, Vol. 1A, Amsterdam: Elsevier Science Publishers, $707-753$

Hampton, M.B., 1991, Physician's income and the percent female on the physician's speciality, Economics Letters 36, 425-428

Hampton, M.B. and J.S. Heywood, 1993, Do workers accurately perceive gender wage discrimination, Industrial and Labor Relations Review 47, 36-49

Hellerstein, J.K., D. Neumark and K.R. Troske, 2002, Market forces and sex discrimination, Journal of Human Resources 28, 353-380

Jones, F.L., 1983, On decomposing the wage gap: A critical comment on Blinder's method, Journal of Human Resources 18, 126-130

Kehrer, B.H., 1976, Factors affecting the incomes of men and women physicians: An exploratory analysis, Journal of Human Resources 11, 526-545

Langwell, K.M., 1982, Factors affecting the incomes of men and women physicians: Further explorations, Journal of Human Resources 17, 261-274

Neumark, D., 1988, Employers' discriminatory behavior and the estimation of wage discrimination, Journal of Human Resources 23, 279-295

Oaxaca, R.L., 1973, Male-Female wage differentials in urban labor markets, International Economic Review 14, 693-709

Oaxaca, R.L. and M.R. Ransom, 1994, On discrimination and the decomposition of wage differentials, Journal of Econometrics 61, 5-21

Oaxaca, R.L. and M.R. Ransom, 1999, Identification in detailed wage decompositions, Review of Economics and Statistics 81, 154-157

Ohsfeldt, R.L. and S.C. Culler, 1986, Differences in income between male and female physicians, Journal of Health Economics 5, 335-346 
Olivetti, C. and B. Petrongolo, 2008, Unequal pay or unequal employment? A cross-country analysis of gender gaps, Journal of Labor Economics 26, 621654

Ponthieux, S. and D. Meurs, 2005, The gender wage gap in Europe: Women, men and the public sector, unpublished paper, INSEE

Reimers, C.W., 1983, Labor market discrimination against the hispanic and black men, Review of Economics and Statistics 65, 570-579

Rizzo, J.A. and C. Blumenthal, 1994, Physician labor supply: Do income effects matter?, Journal of Health Economics 13, 433-453

Rizzo, J.A. and R. Zeckhauser, 2006, Pushing incomes to reference points: Why do male doctors earn more?, Journal of Economic Behavior $\mathscr{E}_{3}$ Organization, forthcoming

Smith, D.M., 2002, Pay and productivity differences between male and female veterinarians, Industrial and Labor Relations Review 55, 493-511

Weichselbaumer, D. and R. Winter-Ebmer, 2003, A meta-analysis of the international gender wage gap, Journal of Economic Surveys 19, 479-511

Weichselbaumer, D. and R. Winter-Ebmer, 2007, The effects of competition and equal treatment laws on gender wage differentials, Economic Poliy $22,235-287$

White, H., 1980, A heteroskedasticity-consistent covariance matrix estimator and a direct test for heteroskedasticity. Econometrica 48, 817-838

Wood, R.G., M.E. Corcoran and P.N. Courant, 1993, Pay differences among the highly paid: The male-female earnings gap in lawyers' salaries, Journal of Labor Economics 11, 417-441

\section{Appendix}

Data sources: Information on the annual earnings of the physicians and their activity levels between 2000 and 2004 are covered by the 'Gebietskrankenkasse' of the Austrian province of Tyrol. Additionally, we use the following information on individual characteristics of contracted physicians and the physicians labor market from this province:

- Hours worked, days not worked, services by appointment, age, residential length, specialities, additional individual characteristics (own held pharmacy, emergency certificate, medical district doctor, school physician, temporary appointment outside): Österreichische Ärztekammer, Ärzteliste (official index of the Austrian chamber of physicians), various years.

- Income (average wage income per employed person), population, area, tourist accommodations, in- and out-commuters: Statistical handbook of the local government of Tyrol, various years.

- Number of physicians in the medical district with and without a contract are covered by the above cited 'Ärzteliste'. 
Descriptive statistics: Table A1 


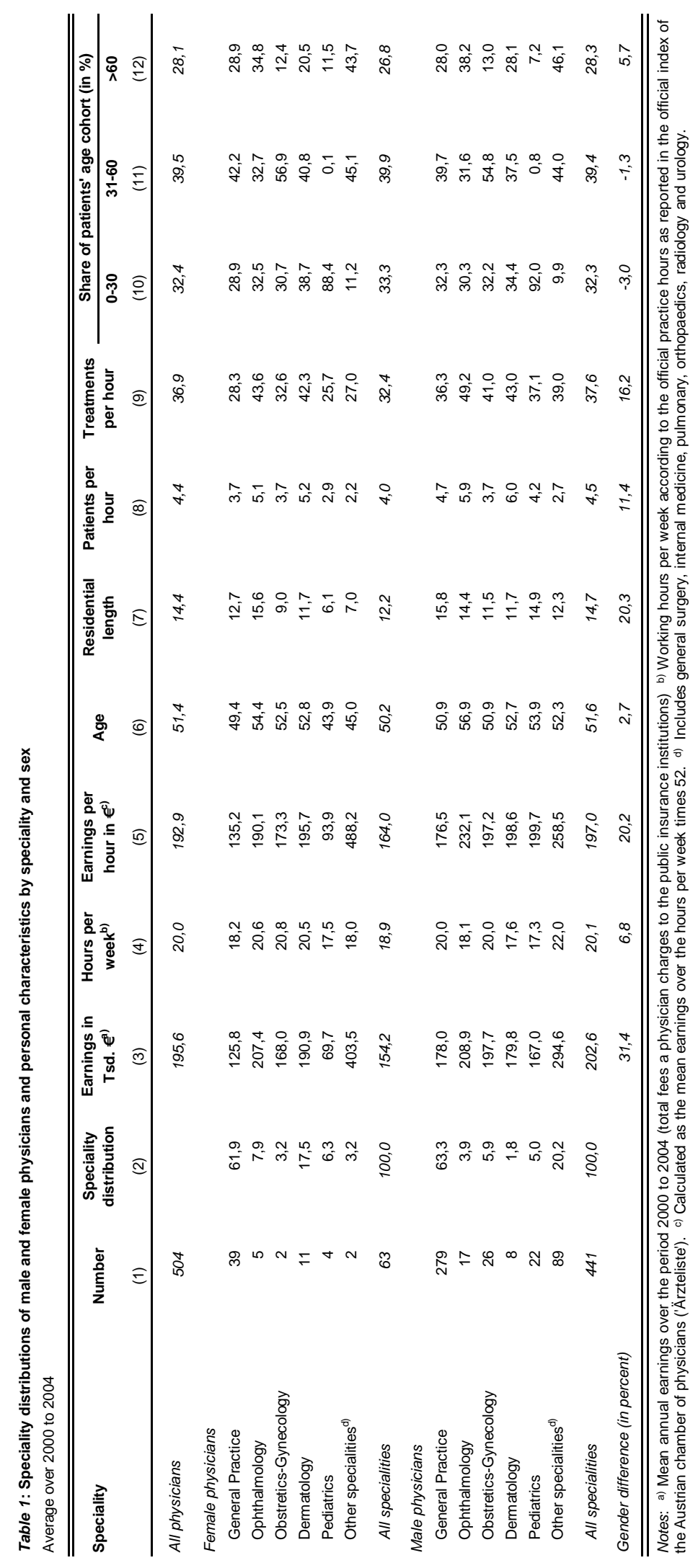




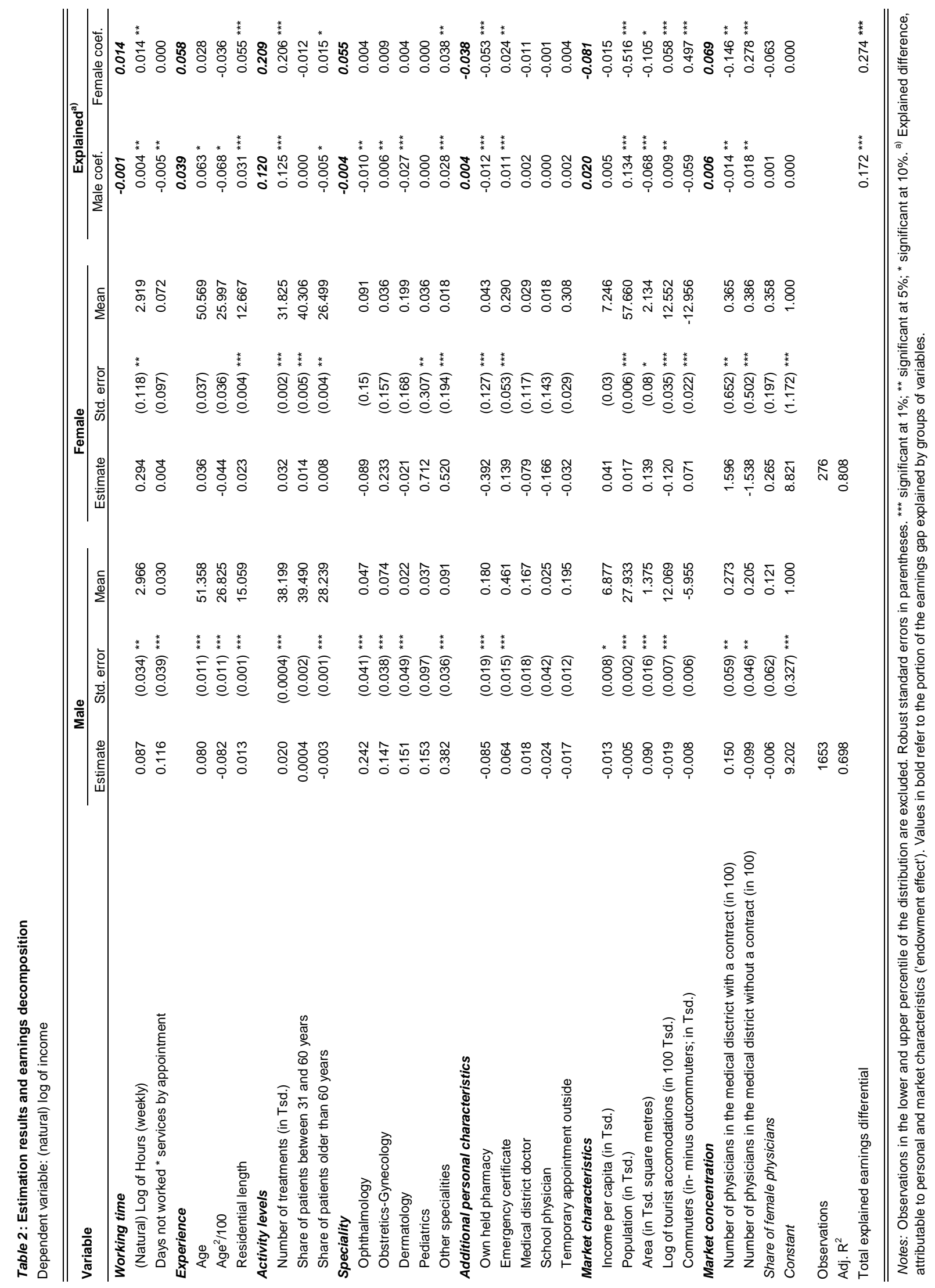




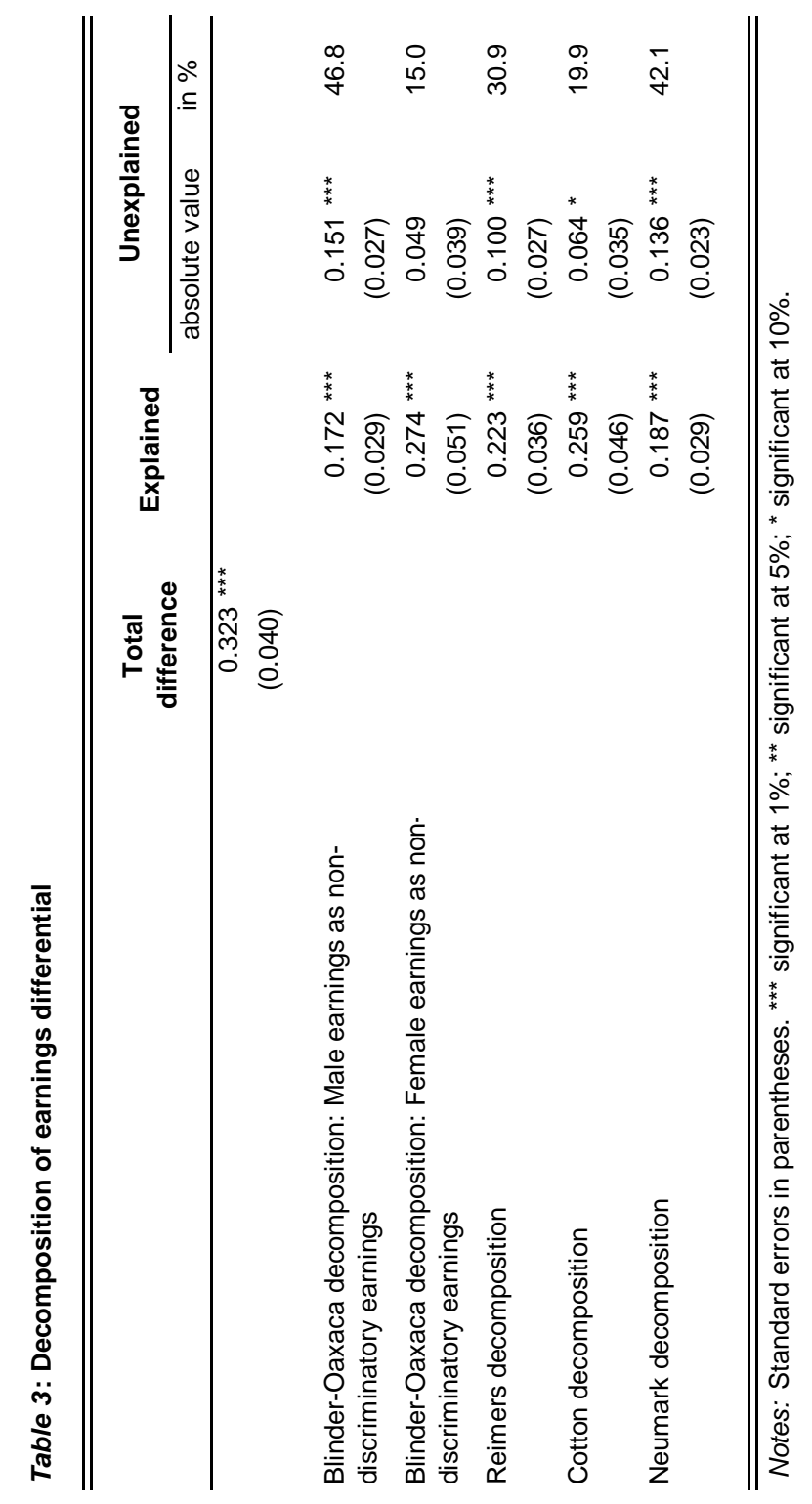




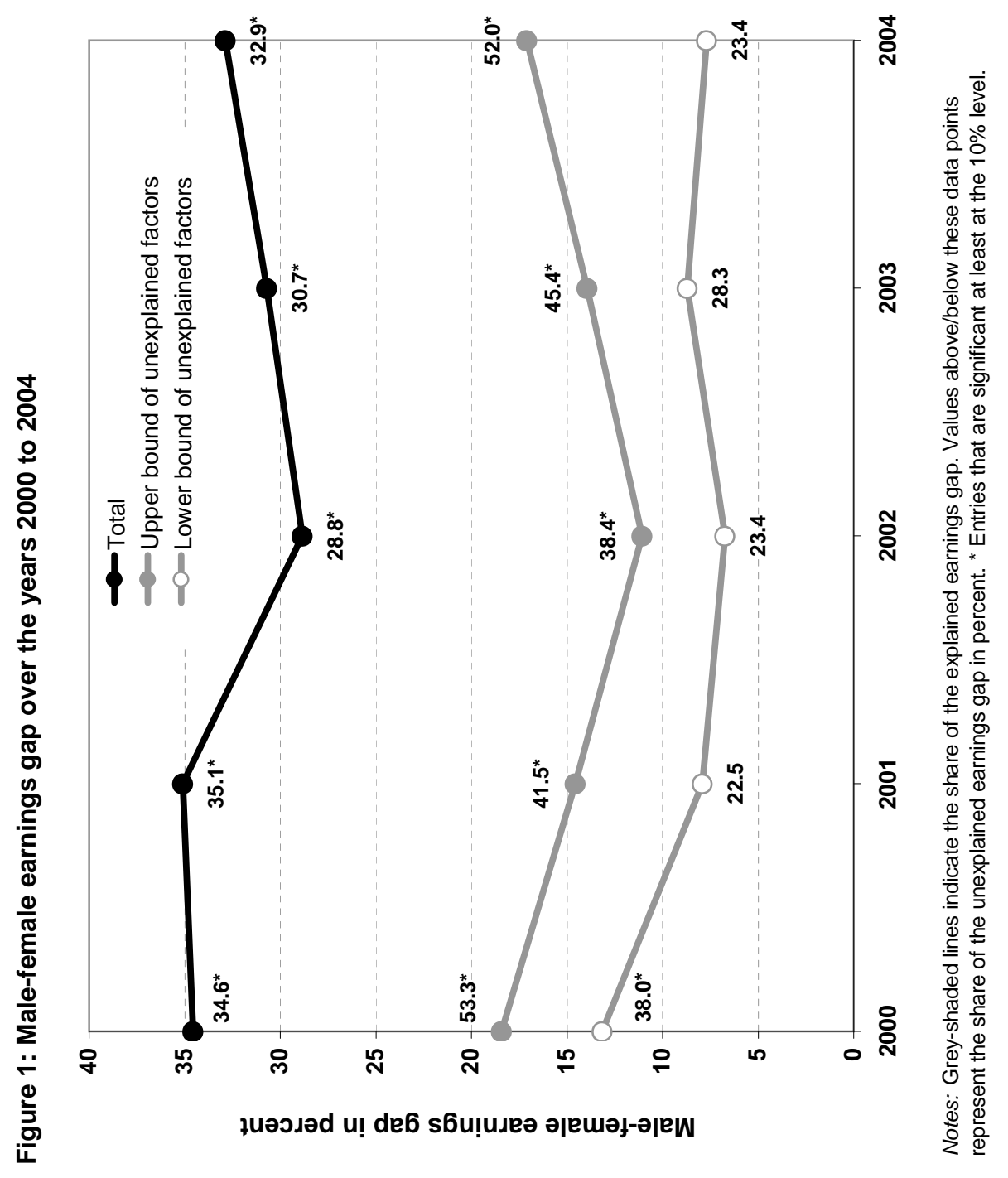




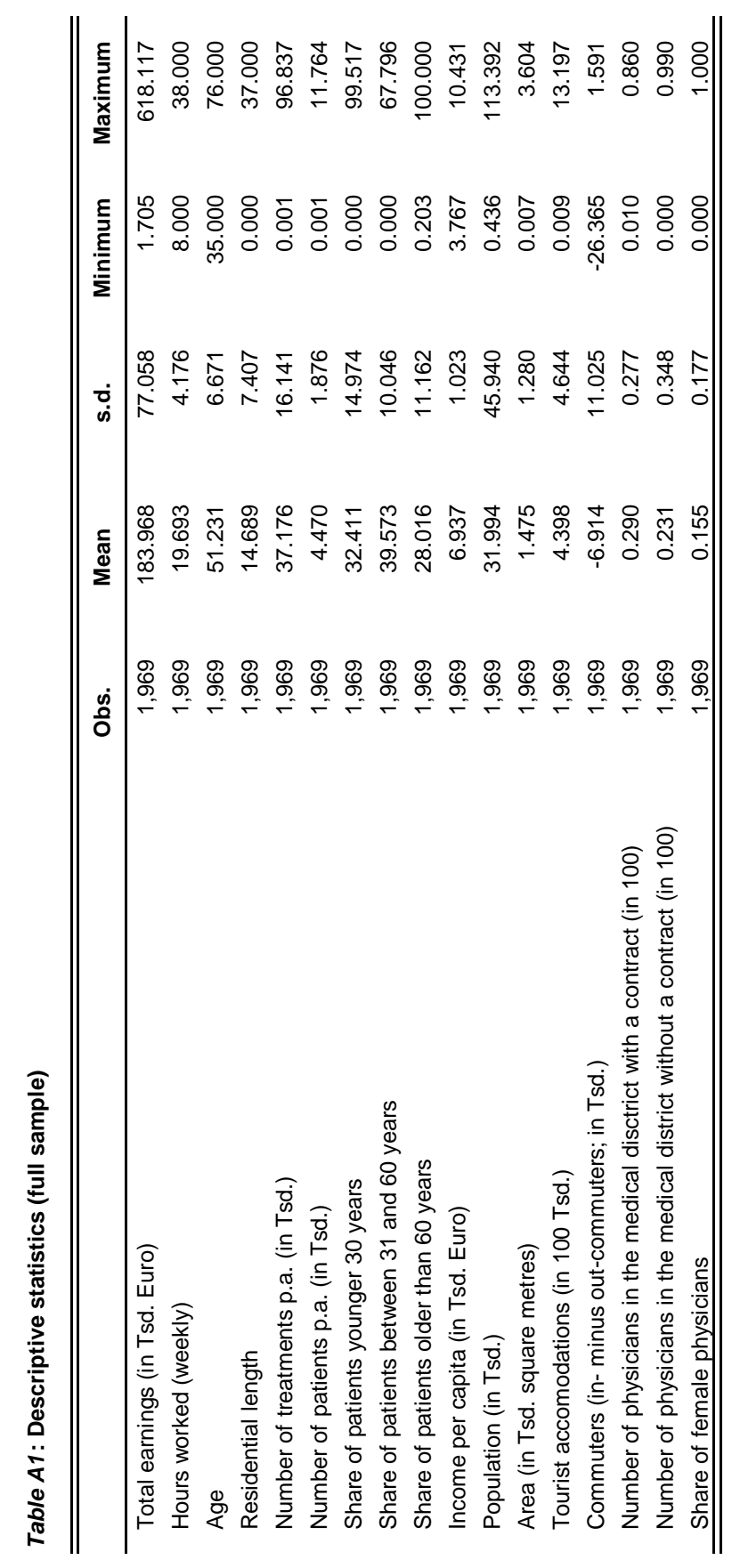

